\title{
Portfolio om de basisarts-in-opleiding te begeleiden
}

\author{
K. Overeem, E.W. Driessen, J. van Tartwijk, C.P.M. van der Vleuten
}

\section{Samenvatting}

Inleiding: Binnen het hoger onderwijs is het portfolio de laatste jaren aan een opmerkelijke opmars bezig. De belangstelling voor het werken met portfolio's komt voort uit de omschakeling die binnen veel opleidingen wordt gemaakt, van een traditioneel, vakgericht curriculum naar een op competentie-ontwikkeling gericht curriculum. In het portfolio analyseert en evalueert de student het eigen functioneren en formuleert verbeterpunten voor zichzelf. Portfolio's zijn dan ook vooral zinvol wanneer studenten een uniek ontwikkeltraject doorlopen. Het portfolio kan grofweg voor drie functies worden ingezet: volgen, begeleiden en beoordelen van de competentie-ontwikkeling van de student. De centrale vraagstelling van dit artikel luidt: welke meerwaarde kan het portfolio hebben voor geneeskunde-opleidingen en hoe kan het portfolio worden ingericht?

Beschrijving: Het Maastrichtse geneeskundeportfolio is ingedeeld rond vier rollen die de basisarts moet kunnen vervullen, welke zijn gebaseerd op het landelijke Raamplan. Studenten worden bij het samenstellen van het portfolio begeleid door een mentor. Aan het eind van het jaar wordt het portfolio beoordeeld volgens een vaste procedure. Uit de eerste ervaringen van studenten blijkt dat zij het werken met het hier beschreven portfolio zinvol vinden. Het stimuleert hen tot het opstellen van een sterkte-zwakteanalyse en het formuleren van leerdoelen.

Discussie: De belangrijkste meerwaarde van portfolio's voor het geneeskunde-onderwijs is dat het portfolio aansluit bij ervaringen over het leren en functioneren in de praktijk. Zo wordt optimaal gebruik gemaakt van leersituaties uit de praktijk die tijdens de geneeskundeopleiding aan bod komen. Naar aanleiding van de reflectie op het eigen handelen worden leerdoelen geformuleerd, welke een belangrijke impuls vormen voor een verbetering van de eigen taakvervulling in de praktijk. (Overeem K, Driessen EW, Tartwijk J van, Vleuten CPM van der. Portfolio om de basisarts-in-opleiding te begeleiden. Tijdschrift voor Medisch Onderwijs 2003;22(6): 268-276.)

\section{Inleiding}

Portfolio's maken een opmerkelijke opmars binnen het hoger onderwijs. Deze belangstelling is het gevolg van de onderwijsvernieuwingen die veel opleidingen op dit moment doormaken. Hierbij vindt een verschuiving plaats van traditionele curricula gericht op kennis en/of vaardigheden naar curricula waarin de ontwikkeling van competenties een centrale plaats heeft. Waar in traditionele curricula de nadruk lag op beroepsgebonden vaardig- heden (bijvoorbeeld het vermogen om taken te kunnen vervullen als het stellen van een differentiaal diagnose of het verrichten van lichamelijk onderzoek) wordt in recentere curricula meer aandacht besteed aan competenties, zoals het beter kunnen vervullen van taken door goed communiceren, problemen oplossen en plannen. Een belangrijke manier om deze competenties te verwerven is door handelen in de praktijk (ervaringsleren). Het gaat er om in verschillende opleidings- en 
praktijkcontexten taken uit te voeren, telkens het bereikte resultaat te evalueren en na te gaan wat al lukt en wat nog niet. Vervolgens zal gericht gewerkt moeten worden aan de geformuleerde leerpunten.

Een portfolio wordt gezien als de methode bij uitstek om dat ervaringsleren zichtbaar en dus bespreekbaar en beoordeelbaar te maken. ${ }^{1}$ In een portfolio kan een student overzichten geven van waar aan welke taken is gewerkt, aan de hand van allerhande materiaal laten zien hoe dat is gegaan en door systematische schriftelijke reflecties daarop duidelijk maken waar hij leerpunten ziet. Het portfolio kan grofweg voor drie functies worden ingezet: volgen, begeleiden en beoordelen. Gaat het erom te volgen waar studenten welke taken uitvoeren, dan zal de nadruk in het portfolio vooral liggen op overzichten. Gaat het erom te beoordelen welk niveau ze hebben bereikt bij het uitvoeren van taken, dan is het materiaal in het portfolio belangrijk. Gaat het er tenslotte om de samensteller te begeleiden bij zijn leerproces, dan zijn de reflecties van de student van groot belang (zie ook figuur 1).

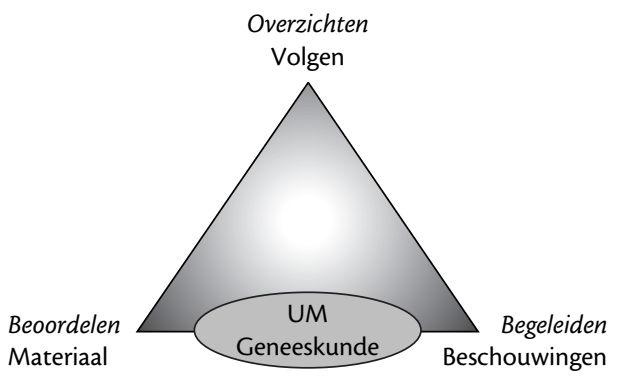

Figuur 1. Verschillende doelen van gebruik van portfolio.

De consequentie van de verschillende doelen die opleidingen hebben met het portfolio is dat het begrip portfolio niet verwijst naar één instrument, maar naar een breed scala aan instrumenten. Er is geen absolute standaard voor het werken met portfolio's, en positieve of negatieve ervaringen van de ene opleiding hebben zeker niet automatisch voorspellende waarde voor andere opleidingen. Geneeskundeopleidingen die het zinvol vinden om zicht te krijgen op het ervaringsleren van hun studenten, moeten zich afvragen wat hun doelen zijn: volgen, begeleiden en/of beoordelen van dat ervaringsleren. Op basis daarvan kunnen ze een portfolio ontwikkelen waarmee die doelen het best worden gediend.

De ervaring leert dat het werken met portfolio's minder eenvoudig is dan het lijkt. ${ }^{2}$ Niet alleen organisatorisch maar ook inhoudelijk dienen tal van vragen beantwoord te worden om onderwijsvernieuwing waarin portfolio's een rol spelen tot een succes te maken.

In dit artikel geven we daar aanzetten toe. Centraal staat de vraag: welke meerwaarde kan een portfolio hebben voor geneeskunde-opleidingen en hoe kan het portfolio worden ingericht?. We maken daarbij gebruik van de ervaringen van de Faculteit der Geneeskunde in Maastricht. Deze bijdrage is in de eerste plaats bedoeld om $\mathrm{u}$ als lezer praktische wenken te geven voor het werken met portfolio's. Daarnaast willen we u ook inzicht bieden in het waarom van de beschreven keuzes.

\section{Beschrijving}

\section{Het Maastrichtse geneeskundeportfolio}

De Maastrichtse geneeskunde-opleiding zet het portfolio in de eerste studiejaren in om de competentieontwikkeling van eerste- en tweedejaarsstudenten te begeleiden en te beoordelen. Reflecties hebben een centrale plaats in het geneeskunde portfolio van de Universiteit Maastricht (zie figuur1). In de latere leerjaren krijgt het portfolio ook een rol bij het beoordelen van de diverse competenties waartoe 
wordt opgeleid. In deze bijdrage focussen we op de rol van het portfolio in de eerste studiejaren.

\section{Portfolio als methode om studenten te begeleiden}

Beschouwingen of reflecties op het eigen leren en functioneren in de praktijk hebben een centrale plaats in het begeleidingsportfolio. Reflectie, opgevat als zelfregulatie of het vermogen om het eigen handelen op basis van systematische evaluatie en analyse te verbeteren, speelt een centrale rol in de begeleiding van praktijkleren. Voor de begeleiding van studenten die reflecteren op het eigen handelen aan de hand van een portfolio, kunnen onder meer aanknopingspunten worden gevonden in het werk van Korthagen. ${ }^{3}$ Korthagen ontwikkelde een spiraalmodel van reflectie waarin de wisselwerking tussen handelen en leren van dat handelen centraal staat (zie figuur 2).

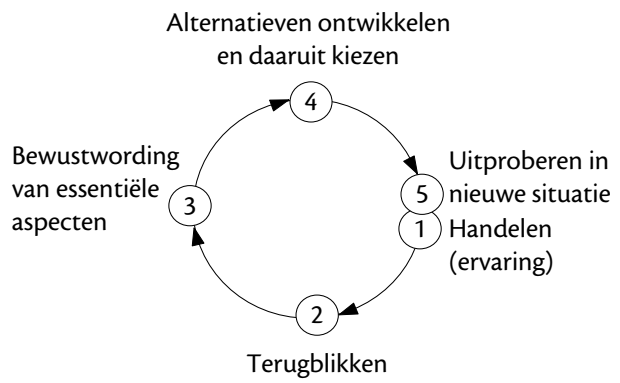

Figuur 2. Spiraalmodel van reflectie volgens Korthagen.

Het samenstellen en bespreken van een portfolio in een opleidingscontext laat zich goed met dit model beschrijven. Het verzamelen van materiaal en het beschrijven van de taakvervulling zal meestal impliceren dat systematisch wordt teruggeblikt op het eigen handelen (fase 2) en dat dit handelen wordt geanalyseerd en geë- valueerd. Vervolgens zal de student essentiële aspecten van bepaalde competenties ontdekken die aandacht behoeven (fase 3). In deze fase kan de student bijvoorbeeld uitzoeken waarom het in de praktijk anders gaat dan hij had verwacht. Voor een begeleider biedt het portfolio inzicht in de mate waarin de samensteller al over de gevraagde competenties beschikt. Daarnaast biedt de analyse en evaluatie van dat handelen door de samensteller handvatten voor gerichte feedback en voor het eventueel ontwikkelen van alternatieven (fase 4). Een dergelijke, systematische werkwijze kan beschouwd worden als een vorm van zelfbeoordeling. ${ }^{1}$ Immers, de samensteller van het portfolio evalueert zelf de kwaliteit van de wijze waarop de taak is uitgevoerd. Die zelfbeoordeling speelt vervolgens een sturende rol in het verdere leerproces. Een begeleider geeft feedback op die zelfbeoordeling. Hij is beoordelaar in de zin dat bewaakt wordt of de kwaliteit van de zelfbeoordeling voldoende is. Door in de eigen analyse systematisch te verwijzen naar het opgenomen materiaal, krijgt dat materiaal een functie als bewijsmateriaal voor de beweringen van de student. Voor begeleiders biedt deze werkwijze snel inzicht in de manier waarop de student de eigen competentie-ontwikkeling ziet.

Doel van deze vorm van begeleiding is dat de student leert de eigen ontwikkeling zelf te sturen: leren leren.

\section{Het portfolio}

De Maastrichtse Faculteit der Geneeskunde gebruikt het portfolio nu om haar eerste- en tweedejaarsstudenten te begeleiden bij hun competentie-ontwikkeling. Het portfolio vormt een verplicht onderdeel van het curriculum en wordt naast andere vormen van toetsing gebruikt. In het portfolio worden vier rollen onderscheiden, ontleend aan het Raamplan: ${ }^{4}$ 
- De arts als medisch expert.

- De arts als wetenschapper.

- De arts als werker in de gezondheidszorg.

- De arts als persoon.

Verder dient het portfolio nog een curriculum vitae, een algemeen deel en bijlagen te bevatten. Deze verplichte onderdelen van het portfolio zijn als tabbladen opgenomen in de portfoliomap, die alle studenten krijgen. Voor deze structuur is gekozen om studenten op weg te helpen bij het maken van een zelfanalyse. Voor elke rol in het portfolio zijn de competenties waarover een basisarts volgens het Raamplan dient te beschikken, vertaald naar het niveau van zowel eersteals tweedejaarsstudenten. De student beschrijft per rol zijn ontwikkeling van de verschillende competenties. De beweringen in de zelfanalyse van de student dienen te worden ondersteund met bewijsmateriaal. De student is vrij in de keuze van bewijsmateriaal. Typische voorbeelden van veel gebruikte materialen zijn: selecties uit zelfgemaakte powerpointpresentaties met de feedback op de presentatie, voorgangstoetsscores, feedback op simulatiepatiëntcontacten, fragmenten uit gemaakte verslagen.

De aansturing van de samensteller van een portfolio moet voldoen aan twee eisen: duidelijkheid in casu structuur en vrijheid. Duidelijkheid is vereist zodat studenten weten wat er van hen wordt verwacht.5-6 Vrijheid is belangrijk omdat zonder die vrijheid het werken aan het portfolio gemakkelijk ontaardt in een invuloefening. Wanneer teveel aan het portfolio wordt voorgeschreven is het risico groot dat de student het portfolio routinematig 'invult' en de reflectie op de eigen ontwikkeling minder uit de verf komt. ${ }^{6-7}$ In de opzet van het Maastrichtse geneeskundeportfolio is geprobeerd aan deze twee eisen te voldoen. Daarom is er een handleiding gemaakt met daarin een beschrijving van de vier beroepsrollen, voorbeeldfragmenten van sterkte-zwakteanalyses en competentie-eisen en richtvragen, om structuur en duidelijkheid te bieden. Daarnaast zijn studenten vrij om te kiezen wat ze in hun portfolio opnemen en waar ze nadruk willen leggen; op deze manier is het portfolio een persoonlijk document.

Om dit alles te illustreren is als voorbeeld in tabel 1 een fragment van de rol als wetenschapper uit de propedeusehandleiding genomen en een fragment van een door een student geschreven reflectie hierop.

\section{De procedure}

In jaar 1 vindt een uitgebreide introductie plaats van het begrip portfolio. Ten eerste wordt om te oefenen met het samenstellen van een portfolio in het eerste jaar begonnen met een kennismakingsoefening. Bij deze 'life in a bag' oefening is de tas een metafoor voor het portfolio. ${ }^{8}$ De student wordt gevraagd enkele voorwerpen mee te nemen die veel over hem zeggen als persoon. De student moet een voorwerp selecteren om dit vervolgens te presenteren aan medestudenten en de mentor. Op deze manier wordt geoefend met het begrip zelfreflectie. Ten tweede wordt tijdens een informatiebijeenkomst het hoe en waarom van het portfolio toegelicht voor alle eerstejaarsstudenten.

Vervolgens gaan de studenten zelf aan de slag en dienen zij twee keer per jaar het portfolio samen te stellen. De student is eigenaar van het portfolio, maar stelt het portfolio twee keer per jaar ter beschikking aan zijn mentor. Om ervoor te zorgen dat een zo groot mogelijke impuls wordt gegeven aan een verbetering van het functioneren is een portfoliocyclus opgesteld (zie tabel 2). Studenten wordt geadviseerd 
Tabel 1. Fragment rol als wetenschapper.

\section{Fragment rol als wetenschapper}

Competentie-eis Het kunnen overdragen van wetenschappelijke informatie aan anderen door het houden van een voordracht of het schrijven van een verslag.

Richtvragen - Wat vind je moeilijk en makkelijk bij presenteren?

- Wat zijn de reacties op je presentaties?

- Wat zijn je sterke en zwakke punten bij het schrijven van een verslag?

\section{Fragment sterkte-zwakteanalyse}

Presentatie- $\quad$ Tot nu toe heb ik dit jaar één keer kunnen oefenen met een presentatie die ik moest technieken voorbereiden voor een groep. Daarnaast heb ik uiteraard vaker geoefend met informatie overbrengen tijdens onderwijsgroepen. Dit laatste ging prima, daarbij had ik geen last van te snel spreken (zie beoordelingsformulier professioneel gedrag, bijlage 4). Bij een presentatie die ik moest houden in blok 1.4 had ik het onderwerp grondig bestudeerd, goed nagedacht over doel en structuur van het verhaal en over de opening en voorbeelden (zie beoordelingsformulier presentatie bijlage 5 en de PowerPoint van de presentatie, bijlage 15). Ik had wel geoefend, maar het niet op een cassettebandje opgenomen omdat ik dat echt vervelend vond werken. Op het moment dat ik de zaal in keek, werd ik zenuwachtig en merkte ik dat ik sneller en onduidelijker ging spreken.

Leerdoel Ik wil rustiger leren spreken door, wanneer de situatie zich voordoet, voor een zaal te spreken of een presentatie te houden (ik ben lid van de Tropencommissie en zal enkele keren een praatje gaan houden voor een collegezaal).

Tabel 2. Stappenplan voor het samenstellen van een portfolio.

\begin{tabular}{|c|c|c|c|c|}
\hline \multirow{4}{*}{ Terugblikken $<$} & Stap 1 & $\rightarrow$ & $\begin{array}{l}\text { Eisen } \\
\text { Richtvragen } \\
\text { Leerdoelen }\end{array}$ & $\begin{array}{l}\text { Bekijk de eisen en richtvragen uit de hand- } \\
\text { leiding en kijk naar je leerdoelen van de } \\
\text { vorige periode. Over deze competenties ga } \\
\text { je materiaal verzamelen. }\end{array}$ \\
\hline & Stap 2 & $\rightarrow$ & $\begin{array}{l}\text { Selectie bewijsmateriaal } \\
\text { Typerende situaties }\end{array}$ & $\begin{array}{l}\text { Verzamel zoveel mogelijk bewijsmateriaal } \\
\text { over jouw functioneren. Denk ook aan } \\
\text { typerende situaties in het onderwijs of de } \\
\text { praktijk die iets zeggen over jouw vaardig- } \\
\text { heden en kennis. }\end{array}$ \\
\hline & Stap 3 & $\rightarrow$ & Sterkte-zwakteanalyse & $\begin{array}{l}\text { Gebruik de eisen en je leerdoelen om per } \\
\text { rol je functioneren en bekwaamheden te } \\
\text { analyseren en zet dit op papier. }\end{array}$ \\
\hline & Stap 4 & $\rightarrow$ & $\begin{array}{l}\text { Ordening } \\
\text { bewijsmateriaal }\end{array}$ & $\begin{array}{l}\text { Zorg voor goede verwijzingen in je sterkte- } \\
\text { zwakteanalyse naar het bewijsmateriaal. }\end{array}$ \\
\hline \multirow[t]{2}{*}{ Vooruitblikken } & Stap 5 & $\rightarrow$ & Leerdoelen & $\begin{array}{l}\text { Denk aan de hand van je sterkte-zwakte- } \\
\text { analyse na over waar je de komende periode } \\
\text { aan wilt werken en probeer je leerdoelen zo } \\
\text { concreet mogelijk te formuleren. }\end{array}$ \\
\hline & Stap 6 & $\rightarrow$ & Leerplan & $\begin{array}{l}\text { Denk na over hoe je in de komende periode } \\
\text { je leerdoelen wilt gaan verwezenlijken. }\end{array}$ \\
\hline
\end{tabular}


om bij het samenstellen van hun portfolio dit stappenplan te doorlopen. In zijn portfolio kijkt de student terug op zijn functioneren en leren van de afgelopen periode. Tijdens een voortgangs- en eindgesprek bespreken student en mentor de ontwikkeling in de afgelopen periode en de kwaliteit van het portfolio. Ook wordt gekeken of er problemen zijn waarvoor de student hulp van de mentor nodig heeft. In het portfolio wordt ook vooruitgeblikt op de komende periode. Hij stelt vast waar leerpunten liggen en hoe hij deze wil bereiken. In het voortgangs- en eindgesprek concretiseert de student met zijn mentor dit in leerdoelen en een leerplan. In het volgende portfolio blikt de student terug of de leerdoelen zijn behaald of niet en begint de portfoliocyclus opnieuw.

\section{De begeleiding}

Reflectie wordt gestimuleerd door met anderen over het eigen leren en handelen te praten, zowel in contacten met andere studenten als door het contact van de student met een mentor. 9-10 Daarom is gekozen voor een begeleidingssysteem van mentoren en mentorgroepen. Een mentor begeleidt in totaal maximaal twintig studenten en zijn rol is tweeledig. Ten eerste stimuleert de mentor reflectie en begeleidt hij de student in het opstellen van een leerplan. De mentor geeft tijdens het voortgangsgesprek en het eindgesprek adviezen over wat kan worden verbeterd aan het portfolio. Ten tweede draagt de mentor zorg voor een meer algemene begeleiding van de studenten uit zijn mentorgroepen.

Om de mentoren goed voor te bereiden worden twee trainingen gegeven. In de eerste training komen het wat en waarom van het portfolio, het geneeskundecurriculum en de mentortaken aan bod. Tijdens de tweede training wordt aan de slag gegaan met echte portfolio's. De mentoren verrichten een aantal simulatieportfolioconsulten met studenten. Gedurende het studiejaar zijn er een aantal intervisiebijeenkomsten.

\section{De beoordeling}

De mentor brengt aan het eind van het jaar een advies uit over de kwaliteit van het portfolio aan de portfoliobeoordelingscommissie, welke bestaat uit alle mentoren. Deze commissie en niet de mentor is dus de formele beoordelingsautoriteit. Om de mentor optimaal in staat te stellen om de student te begeleiden, is hij niet belast met de formele beoordeling. Het portfolio wordt ieder cursusjaar beoordeeld, waarbij drie kwalificaties mogelijk zijn: onvoldoende, voldoende en goed. Bij minimaal een voldoende oordeel worden drie studiepunten toegekend. Omdat het Maastrichtse portfolio is gericht op reflectie, is de kwaliteit van reflectie het belangrijkste onderwerp van beoordeling.

In het eindgesprek bespreekt de mentor zijn gemotiveerde advies met de betreffende student en de student wordt gevraagd of hij hiermee instemt of niet. Als de student niet instemt met het advies dient dit te worden aangegeven op het beoordelingsadviesformulier. Wanneer het advies van de mentor onvoldoende is, heeft de student een week de tijd om het portfolio aan te passen. Alle portfolio's worden beoordeeld door een eerste beoordelaar. Een tweede beoordelaar wordt ingeschakeld wanneer het advies van de mentor en het oordeel van de beoordelaar niet overeen komen of wanneer de student niet heeft ingestemd met het advies van de mentor (zie figuur 3). Van groot belang voor de kwaliteit en betrouwbaarheid van de beoordeling, is een uitgebreide training van de beoordelaars. ${ }^{11-12}$ Wanneer het eindoordeel onvoldoende is, telt het portfolio van het tweede jaar als 


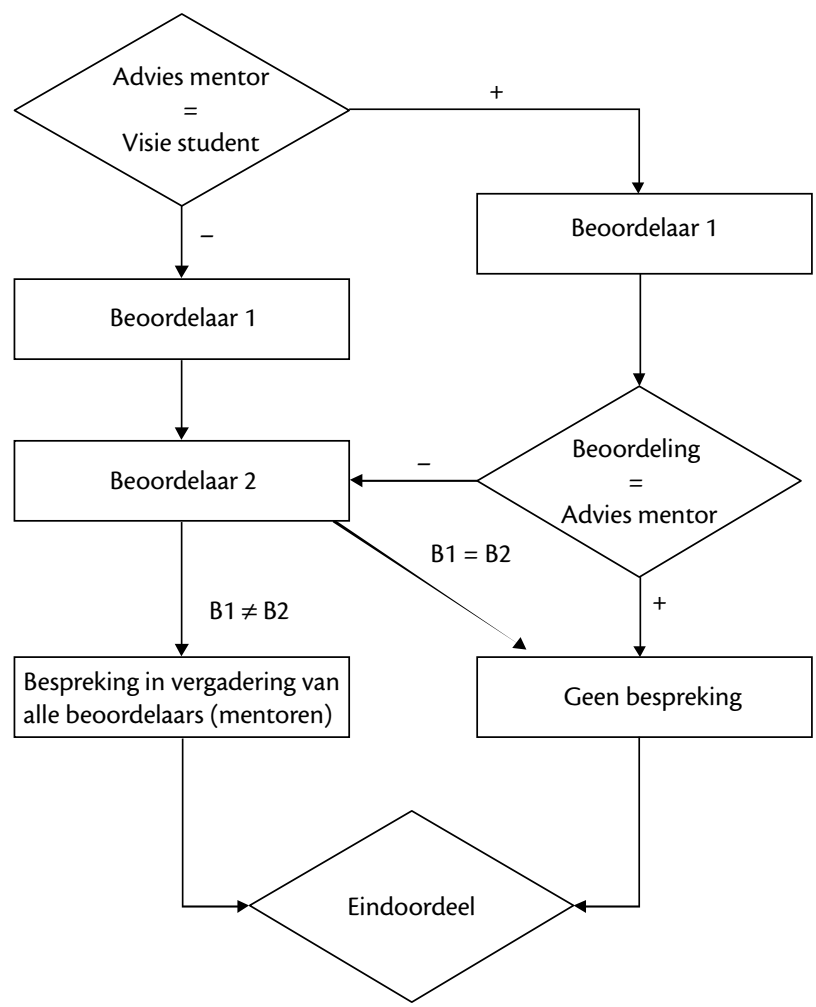

Figuur 3. Beoordelingsprocedure.

herkansing en worden alsnog studiepunten toegekend in het tweede studiejaar.

\section{Eerste ervaringen}

De meerderheid van de eerstejaars geneeskundestudenten in Maastricht vindt het portfolio zinvol en leerzaam. ${ }^{13}$ Volgens hen stimuleert het portfolio om na te denken over sterke en zwakke punten van zichzelf en draagt het portfolio bij aan het opstellen van leerdoelen om zichzelf te verbeteren. Voor het leren reflecteren en het onderkennen van leerbehoeften blijkt de begeleiding van een mentor noodzakelijk.

Het portfolio functioneert ook als een instrument voor kwaliteitszorg. Tijdens interviews met studenten kwam ten eerste naar voren dat er weinig gerichte, persoonlijke feedback wordt gegeven in het onderwijs. Voor studenten is feedback nodig om inzicht te krijgen in hun goede en minder goede kanten. Dit werd duidelijk omdat studenten deze feedback vaak als bewijsmateriaal in het portfolio willen opnemen om aan te tonen of bepaalde competenties of leerdoelen wel of niet zijn bereikt. Hier ligt een knelpunt, maar wanneer dit kan worden opgelost, betekent dit ook een duidelijke kwaliteitsverbetering voor het geneeskunde-onderwijs. Ten tweede kwam naar voren dat studenten vaak geen tweede gelegenheid hebben om hun leerdoelen te verwezenlijken. In het voorbeeld van de rol als wetenschapper heeft deze student als doel minder snel te praten tijdens een presentatie. Maar vervolgens kan het zijn dat hij in het volgende halfjaar niet de mogelijkheid heeft om zichzelf op dit punt te verbeteren. Het 
is dus van belang dat er binnen het onderwijs meer ruimte komt voor de invulling van individuele leertrajecten.

\section{Discussie}

Remmen noemt de verdere invulling en bestudering van portfolio's een uitdaging en geeft als aanbeveling dat opleidingen de meerwaarde van portfolio's moeten nagaan en zich moeten afvragen welke vorm portfolio's moeten aannemen. ${ }^{14}$ Aan de geneeskundefaculteit in Maastricht is in de afgelopen twee jaar het instrument portfolio verder vormgegeven, geïmplementeerd in het onderwijs en nader onderzocht. Een belangrijke meerwaarde van het portfolio is dat studenten inzicht krijgen in hun functioneren en worden gestimuleerd tot vooruitgang in dit functioneren (i.e. het leren leren) en dat dit ervaringsleren ook zichtbaar en meetbaar wordt. Op deze manier kan optimaal gebruik worden gemaakt van leersituaties uit de praktijk die tijdens de geneeskundeopleiding aan bod komen. Met het portfolio dat op dit moment wordt gebruikt worden studenten beoordeeld op hun niveau van reflectie. De reflecties zoals die in het portfolio zijn opgenomen vervullen de rol van bewijsmateriaal. In de toekomst zullen competenties (mede) aan de hand van het portfolio worden beoordeeld. Op dat moment zal aandacht gegeven moeten worden aan het identificeren van documentatiemateriaal dat de student in het portfolio opneemt om aan te tonen dat hij of zij over het vereiste competentieniveau beschikt. In de in figuur 1 gepresenteerde driehoek zal het geneeskunde-portfolio opschuiven in de richting van beoordelen.

Het portfolio kan een belangrijk instrument zijn voor het begeleiden en beoordelen van geneeskundestudenten. Echter, er is nog altijd veel onbekend over hoe de potentiële mogelijkheden van het portfolio benut kunnen worden. Hiervoor is het nodig dat de komende jaren meer onderzoek wordt verricht naar vragen als:

- In hoeverre zet het portfolio aan tot academische en professionele competentieontwikkeling?

- Wat is de kwaliteit van de zelfbeoordeling?

- Wat is het lange termijn effect van reflectie en het opstellen van leerdoelen om zichzelf te verbeteren?

- Hoe betrouwbaar is de beoordeling van een portfolio?

\section{Literatuur}

1. Tartwijk J van, Beijaard D, Driessen EW, Vleuten CPM van der. Portfolio's in het hoger onderwijs. In: Driessen EW, Beijaard D, Tartwijk J van, Vleuten CPM van der. Portfolio's. Groningen: WoltersNoordhoff; 2002. p. 11-8.

2. Beijaard D, Driessen EW, Tartwijk J van, Vleuten CPM van der. Portfolio verder uitgewerkt. In: Driessen EW, Beijaard D, Tartwijk J van, Vleuten CPM van der. Portfolio's. Groningen: WoltersNoordhoff; 2002. p.119-38.

3. Korthagen FAJ. Leren reflecteren: naar systematiek in het leren van je werk als docent. In: Fonderie-Tierie L, Hendriksen J. Begeleiden van docenten. Baarn: Nelissen; 1998. p. 43-56.

4. Metz JCM, Verbeek-Weel AMM, Huisjes HJ. Raamplan 2001 artsopleiding. Nijmegen: Mediagroep Nijmegen; 2001.

5. Carrol JA, Potthoff D, Huber T. Learning from three years of portfolio use in teacher education. Journal of Teacher Education 1996;47(4):253-62.

6. Gearhart MG, Wolf SA. Issues in portfolio assessment: writing processes from their products. Educational Assessment 1997;4(4):265-96.

7. Wade RC, Yarbrough DB. Portfolios: a tool for reflective thinking in teacher education? Teaching \& Teacher Education 1996;12(1):63-79.

8. Krause S. Portfolios in teacher education: effects of instruction on preservice teachers' early comprehension of the portfolio process. Journal of Teacher Education 1996;47(2):130-8.

9. Golberg GL, Roswell BS, Michaels H. Can assessment mirror instruction? A look at peer response and revision in a large-scale writing test. Educational Assessment 1996;3(4):287-314.

10. Wolf K, Whinery B, Hagerty P. Teaching portfolios and portfolio conversations for teacher educators and teachers. Action in Teacher Education 1995;17(1):30-9. 
11. Koretz D. Large scale portfolio assessments in the US: evidence pertaining to the quality of measurement. Assessment in Education 1998;5(3):30934.

12. Friedman Ben David M, Davis MH, Harden RM, Howie PW, Ker J, Pippard MJ. AMEE Medical Education Guide No. 24: portfolios as a method of student assessment. Med Teach 2001;23(6):53551.

13. Driessen EW, Tartwijk J van, Vermunt JD, Vleuten CPM van der. Use of portfolios in early undergraduate medical training. Med Teach 2003;25(1):18-23.

14. Remmen R. Portfolio's in medisch onderwijs: trend, valkuil of hulpmiddel? Tijdschrift voor Medisch Onderwijs 2002;21(2):84-7.

\section{De auteurs:}

Drs. K. Overeem is student-assistent bij de Capaciteitsgroep Onderwijsontwikkeling en Onderwijsresearch, Faculteit der Geneeskunde, Universiteit Maastricht.
Drs. E.W. Driessen is universitair docent bij de Capaciteitsgroep Onderwijsontwikkeling en Onderwijsresearch, Faculteit der Geneeskunde, Universiteit Maastricht en coördinator van een portfolioproject in Maastricht.

Dr. J. van Tartwijk is universitair docent bij het IVLOS in Utrecht en coördinator van een portfolioproject aan de Rijksuniversiteit Utrecht.

Prof. dr. C.P.M van der Vleuten is voorzitter van de Capaciteitsgroep Onderwijsontwikkeling en Onderwijsresearch, Faculteit der Geneeskunde, Universiteit Maastricht.

\section{Correspondentieadres:}

Drs. K. Overeem, Universiteit Maastricht, Faculteit der Geneeskunde, Capaciteitsgroep Onderwijsontwikkeling en Onderwijsresearch, Postbus 616, 6200 MD Maastricht, tel: 043-388 4167,k.overeem@student.unimaas.nl of e.driessen@educ.unimaas.nl.

\section{Summary}

Introduction: Within higher education, the portfolio has gained substantial interest over the past years. This can probably be explained by the changes many of these institutes are going through: the switch from a curriculum aimed at the development of knowledge towards one that aims to develop competencies. In a portfolio, students analyse and evaluate their own functioning and formulate learning objectives for themselves. Portfolios are thus useful when a curriculum allows for individual pathways. Basically, a portfolio can be used for three goals: following, guiding and assessing the competency-development of students. The central research question is: which added value can the portfolio have for medical education and how can the portfolio-system be structured?

Description: The portfolio of the Maastricht Faculty of Medicine is divided into four roles which an undergraduate medical student should be able to perform. These roles are based on the national blueprint of competencies. Students are guided by a mentor when composing a portfolio. At the end of the year, the portfolio is assessed, using an efficient assessment procedure. The first experiences show that students find working with a portfolio useful. It stimulates them to develop a strengths-weaknesses analysis and to formulate learning goals.

Discussion: For medical education, the main added value of a portfolio is that it is closely linked with practical learning and functioning experiences. This way, the practical learning situations medical education offers are used to their fullest. The reflection on your own functioning, leads to formulating learning objectives which form an important stimulus for the improvement of your own functioning. (Overeem $K$, Driessen EW, Tartwijk J van, Vleuten CPM. van der. Portfolio to coach undergraduate medical students. Dutch Journal of Medical Education 2003;22(6): 268-276.) 